\title{
(C) OPEN ACCESS \\ Multifactorial interventions for preventing falls in older people living in the community: a systematic review and meta-analysis of 41 trials and almost 20000 participants
}

\author{
Sally Hopewell, ${ }^{\circledR}$ Bethan Copsey, Philippa Nicolson, Busola Adedire, Graham Boniface, \\ Sarah Lamb
}

\begin{abstract}
- Additional material is published online only. To view please visit the journal online (http://dx.doi.org/10.1136/ bjsports-2019-100732).
\end{abstract}

Nuffield Department of Orthopaedics, Rheumatology and Musculoskeletal Sciences, University of Oxford, Oxford, UK

\section{Correspondence to} Dr Sally Hopewell, Nuffield Department of Orthopaedics, Rheumatology and Musculoskeletal Sciences, University of Oxford, Oxford OX3 7LD, UK:

sally.hopewell@csm.ox.ac.uk

Accepted 24 July 2019

Check for updates

(C) Author(s) (or their employer(s)) 2019. Re-use permitted under CC BY-NC. No commercial re-use. See rights and permissions. Published by BMJ.

To cite: Hopewell $\mathrm{S}$ Copsey B, Nicolson P, et al. Br J Sports Med Epub ahead of print: [please include Day Month Year]. doi:10.1136/ bjsports-2019-100732

\section{ABSTRACT}

Objective To assess the longer term effects of multifactorial interventions for preventing falls in older people living in the community, and to explore whether prespecific trial-level characteristics are associated with greater fall prevention effects.

Design Systematic review with meta-analysis and meta-regression.

Data sources MEDLINE, EMBASE, CINHAL, CENTRAL and trial registries were searched up to 25 July 2018.

Study selection We included randomised controlled trials ( $\geq 12$ months' follow-up) evaluating the effects of multifactorial interventions on falls in older people aged 65 years and over, living in the community, compared with either usual care or usual care plus advice.

Review methods Two authors independently verified studies for inclusion, assessed risk of bias and extracted data. Rate ratios (RaR) with 95\% Cls were calculated for rate of falls, risk ratios (RR) for dichotomous outcomes and standardised mean difference for continuous outcomes. Data were pooled using a random effects model. The Grading of Recommendations, Assessment, Development and Evaluation was used to assess the quality of the evidence.

Results We included 41 trials totalling 19369 participants; mean age 72-85 years. Exercise was the most common prespecified component of the multifactorial interventions ( $85 \% ; n=35 / 41$ ). Most trials were judged at unclear or high risk of bias in $\geq 1$ domain. Twenty trials provided data on rate of falls and showed multifactorial interventions may reduce the rate at which people fall compared with the comparator (RaR 0.79, $95 \% \mathrm{Cl} 0.70$ to $0.88 ; 20$ trials; 10116 participants; $\mathrm{I}^{2}=90 \%$; low-quality evidence). Multifactorial interventions may also slightly lower the risk of people sustaining one or more falls (RR $0.95,95 \% \mathrm{Cl} 0.90$ to 1.00; 30 trials; 13817 participants; $I^{2}=56 \%$; moderatequality evidence) and recurrent falls (RR $0.88,95 \% \mathrm{Cl}$ 0.78 to $1.00 ; 15$ trials; 7277 participants; $I^{2}=46 \%$; moderate-quality evidence). However, there may be little or no difference in other fall-related outcomes, such as fall-related fractures, falls requiring hospital admission or medical attention and health-related quality of life. Very few trials $(n=3)$ reported on adverse events related to the intervention. Prespecified subgroup analyses showed that the effect on rate of falls may be smaller when compared with usual care plus advice as opposed to usual care only. Overall, heterogeneity remained high and was not explained by the prespecified characteristics included in the meta-regression.

\section{What is already known}

- Falls and fall-related injuries are a common and serious problem in older people living in the community. Multifactorial interventions (which target two or more risk factors for falls) are the National Institute for Health and Care Excellence-recommended approach for falls prevention in the UK and recommended as a primary treatment strategy in guidelines for prevention of falls.

- Findings from a previous Cochrane review provided some evidence of the effects of multifactorial interventions in reducing the rate of falls in older people living in the community compared with usual care.

What are the new findings

- Multifactorial interventions may prevent falls in older people living in the community and may slightly reduce the risk of people sustaining one or more falls and recurrent falls (defined as two or more falls within a specified time period). There may be little or no long-term benefit on other fall-related outcomes (eg, such as fracture).

- The most common component included as part of the multifactorial interventions was exercise.

- The effect on rate of falls may be smaller when compared with usual care plus non-tailored falls prevention advice (ie, in either written, audio or visual format) as opposed to usual care only (ie, no change to usual activities).

Conclusion Multifactorial interventions (most of which include exercise prescription) may reduce the rate of falls and slightly reduce risk of older people sustaining one or more falls and recurrent falls (defined as two or more falls within a specified time period).

Trial registration number CRD42018102549.

\section{INTRODUCTION}

One-third of community-dwelling people aged 65 years and older fall each year, and this proportion increases with age. ${ }^{12}$ Falls can have serious 
long-term consequences, ${ }^{3-5}$ including loss of independence, morbidity and mortality. ${ }^{6}$ Fall-related risk factors ${ }^{7}$ include advancing age, history of previous falls, muscle weakness, gait and balance problems, poor vision and chronic diseases such as arthritis. Environmental factors such as lack of handrails, poor lighting, slippery or uneven surfaces, use of walking aids and poor footwear can also play a role. ${ }^{8}$ Most falls result from multiple interacting factors ${ }^{1}$ and generally the more risk factors a person has, the greater their chances are of having a fall. In the UK, the National Health Service is estimated to spend around $£ 2$. 3 billion each year on fall-related injuries in people over the age of $65 .^{2}$

Fall prevention interventions aim to minimise known modifiable risk factors for falling, and thereby prevent falls and associated injuries. ${ }^{8}$ Multifactorial interventions are recommended as a primary treatment strategy in a number of international guidelines for prevention of falls. ${ }^{2}{ }^{10}$ Multifactorial interventions require a person to have a minimum of two or more modifiable risk factors for falling and the strategy involves tailoring interventions to each person's particular risk profile. ${ }^{11}$ Hence, within any treatment cohort not all people receive the same combination of interventions. The manner in which multifactorial interventions are delivered varies. In some instances, the assessment and linked interventions are by the same provider. In others, one provider assesses the patient and interventions are provided through referral to other providers. Exercise programmes whether supervised or unsupervised, or involve a mixture of both, form an important part of many multifactorial interventions. ${ }^{11}$ The core interventions that the National Institute for Health and Care Excellence (NICE) guidelines recommend are: strength and balance training exercises, home hazard assessment and intervention, vision assessment and referral, as well as medication review with modification/withdrawal. ${ }^{2}$

A 2018 Cochrane review of interventions to prevent falls in community-dwelling older people showed that multifactorial interventions may reduce the rate of falls compared with usual care (ie, no active fall prevention intervention), but may have little or no effect on other fall-related outcomes. ${ }^{12}$ Estimates of effectiveness have varied over time and trials have struggled to demonstrate a consistent effect of multifactorial interventions over time and in different countries. ${ }^{12-16}$ Variation in follow-up and subtle differences in comparator groups likely contribute to the large levels of study heterogeneity.

We aimed to provide a contemporary synthesis of the effectiveness of multifactorial intervention for preventing falls in older people living in the community and to focus on trials which provide longer term follow-up ( $\geq 12$ months). This duration was selected as it is the accepted minimal duration of follow-up recommended by NICE for robust appraisal of the effectiveness of interventions. ${ }^{17}$ We aimed to explore heterogeneity with meta-regression, and stability of effects over time.

\section{METHODS}

\section{Search strategy}

We searched MEDLINE, EMBASE, CINAHL (up to 25 July 2018), the Cochrane Bone, Joint and Muscle Trauma Group Specialised Register (up to 12 June 2017) and the Cochrane Central Register of Controlled Trials (CENTRAL) (up to 2017 Issue 6) using tailored search strategies (online supplementary appendix 1). We also searched the WHO International Clinical Trials Registry Platform and ClinicalTrials.gov for ongoing and recently completed trials (up to 25 July 2018). There were no language or publication status restrictions.

\section{Study selection}

Two reviewers independently (BC, PN, BA or GB), and in duplicate, screened titles and abstracts of all potentially eligible studies, for which we then obtained full-text reports. Subsequently, reviewers independently perform study selection and data extraction. Any disagreements were resolved by discussion or, if necessary, by consultation with a third reviewer. We included randomised controlled trials, either individual or cluster randomised, that evaluated the effects of a multifactorial intervention designed to prevent falls or fall-related injuries in people aged 65 years or over living in the community. A multifactorial intervention is defined as one in which interventions from two or more main categories of intervention are given to participants, but the interventions are linked to each individual's risk profile (usually assessed using a formal process). ${ }^{18}$

Trials were included where the intervention was compared with either: (1) usual care (ie, no change to usual activities) or an attention control (an intervention not thought to reduce falls such as general health education or social visits); or (2) usual care plus non-tailored falls prevention advice in either written, audio or visual material format.

If the advice included individually tailored feedback on the participants' risk profile or structured contact with health professionals the trial was excluded as this could be consistent with the components of a multifactorial intervention.

Trials with mixed populations (community and higher dependency places of residence) were eligible provided data were available separately, as were those that recruited participants in hospital if most participants were discharged to the community (where most of the intervention was delivered and falls recorded). We excluded trials that tested interventions for preventing falls in people after stroke and with Parkinson's disease, or were quasirandomised.

Our primary outcome was the rate of falls (ie, number of falls per person-years). Secondary outcomes included the risk of: sustaining one or more falls; recurrent falls (defined as two or more falls in a specified time period); one or more fall-related fractures; a fall that required hospital admission; and a fall that required medical attention (eg, attended hospital emergency department, required general practitioner (GP) consultation) and health-related quality of life (measured using validated scale, eg, EQ-5D or similar). We only included trials with $\geq 12$ months' follow-up. If trials reported multiple time points we used the longest duration, or the duration for which most data were reported, if different.

\section{Data extraction and risk of bias assessment}

Reviewers (BC, PN or BA) extracted information independently and in duplicate for the following: trial design (setting, sample size, inclusion and exclusion criteria, comparability of groups, length of follow-up); characteristics of participants (age, gender, ethnicity, high risk of falls, number randomised, analysed, dropouts in each arm); type of intervention (experimental and control components, timing, adherence); and outcomes measured as listed above. We retrieved data from both full-text and abstract reports of trials. Where sources did not provide sufficient information, we attempted to contact study authors for additional details.

Two reviewers (BC, PN or $\mathrm{BA}$ ) independently assessed risk of bias using the Cochrane risk of bias tool ${ }^{19}$ for the following domains: sequence generation; allocation concealment; blinding of participants and personnel (where due to the nature of the interventions, it was not possible to blind the participants and 
personnel); blinding of outcome assessment (assessed separately for: rate of falls and risk of falling; risk of fractures; requiring hospital admission/medical attention); incomplete outcome data including person-years of follow-up; and selective outcome reporting and bias specific to cluster trials. We also assessed bias in the recall of falls due to less reliable methods of ascertainment $\mathrm{t}^{20}$ (ie, where falls were recorded retrospectively, or not monitored continuously throughout the trial) (online supplementary appendix 2). Each of the domains was scored as 'high', 'low' or 'unclear' risk of bias.

To assess the quality of evidence, we used the Grading of Recommendations, Assessment, Development and Evaluation (GRADE) approach that classifies evidence as high, moderate, low or very low based on considerations of risk of bias, consistency, directness, precision and publication bias. ${ }^{21}$

\section{Data synthesis and statistical methods}

Estimates of treatment effect were extracted for each trial. For the rate of falls, we calculated the rate ratio $(\mathrm{RaR})$ with $95 \%$ CIs. The rate of falls is defined as the total number of falls per unit of person time that falls were monitored (eg, falls per person-year). We used the reported RaR and 95\% CIs if available, and used the length of follow-up reported as the proxy if exact person-months of follow-up were not reported. If trials reported both adjusted and unadjusted RaRs, we used the unadjusted estimate unless the adjustment was for clustering. For binary outcomes we calculated the risk ratio (RR) and for continuous outcomes the standardised mean difference (SMD) for outcomes measured using different scales. We used change scores where absolute values were not reported. For trials that were cluster randomised but did not take account for the effect of clustering, we performed adjustments for clustering around units of randomisation using an intraclass correlation coefficient of $0.01 .^{22}$

Where trials were considered sufficiently homogeneous, random effects meta-analysis was performed using RevMan software. Data were pooled using the generic inverse variance method which enables pooling of the adjusted and unadjusted treatment effect estimates. Cumulative meta-analysis was used to explore the effect of the intervention on the rate and risk of falls over time. Statistical heterogeneity of treatment effects between trials was assessed using the $\chi^{2}$ test with a significance level at $\mathrm{p}<0.1$, and the $\mathrm{I}^{2}$ statistic, as per the Cochrane handbook guidance. ${ }^{23}$ We explored potential sources of heterogeneity and variations in the treatment effect by carrying out the following prespecified subgroup analyses, testing for subgroup differences:

1. Trials that included people at high risk of falls versus those at lower risk of falls (eg, comparing trials with participants who present for medical attention because of a fall, or report recurrent falls in the past year, or demonstrate abnormalities of gait and/or balance, vs unselected).

2. Trials where the assessment and range of interventions included at least two of the components recommended by NICE (ie, strength and balance training, home hazard assessment and intervention, vision assessment and referral, medication review with modification/withdrawal) ${ }^{2}$ versus those which did not include these components or where details of the components were unclear.

3. Trials that directly provided treatment to address identified risk factors versus those where the intervention consisted mainly of referral to other services or the provision of information to increase knowledge (eg, increase the person's awareness about their risk factors to enable them to take decisions).
4. Trials where the comparator was usual care versus usual care plus advice (as defined above).

Sensitivity analyses were also conducted to assess the effects of the intervention on falls excluding trials with: inadequate concealment of allocation; inadequate blinding of outcome assessors; incomplete outcome data; and cluster versus individual randomised trials. Where there were $\geq 10$ studies included in the meta-analysis, we assessed possible small study effects $(p<0.1)$ by generating a funnel plot and testing this statistically using a linear regression test (Egger's test).

Where sufficient trials were identified, meta-regression was undertaken using STATA (metareg command) to explore the impact of the following trial-level characteristics and whether they were associated with greater fall prevention effects:

1. Trial design: sample size: $<20 \%$ missing outcome data; type of comparator intervention.

2. Participant characteristics: average age $\geq 75$ years; control rate of falls; selected at high risk of falls.

3. Intervention components: included NICE-recommended components; actively provided treatment to address fall-related risk factors; whether adherence was assessed.

\section{RESULTS}

\section{Description of included studies}

Electronic searches identified 7868 records, after removal of duplicates we screened the titles and abstracts of 4185 records. Full-text articles were assessed for 451 records and resulted in 109 eligible reports of 41 randomised controlled trials and 19 reports of nine registered trials that are not yet published. Figure 1 shows the details of the study selection process and reasons for exclusion. The characteristics of the 41 included trials are summarised in online supplementary appendices 3 and 4.

The 41 trials involved a total of 19369 participants, the median number of participants randomised in each trial was 328 (IQR 221-540); 36 were parallel group and five were cluster randomised. Most trials included two arms (37 trials) and four had three arms. The length of follow-up ranged from 12 to 48 months. Trials were conducted in 14 countries, the most common being the USA (eight trials) and the UK (seven trials). The mean age of participants ranged from 72 to 85 years; most included more women than men. Twenty-four trials included study participants judged to be at higher risk of falls at enrolment.

Of the 41 trials, 30 included at least two of the intervention components recommended by $\mathrm{NICE}^{2}$ and 21 directly provided treatment to address identified risk factors as part of the intervention. Thirty-four trials ${ }^{24-57}$ were compared with usual care and seven trials ${ }^{58-63}$ were compared with usual care plus advice. The most common components included as part of the multifactorial intervention were exercise (35/41 trials) and environment/ assistive technologies (eg, home hazard assessment and modifications, referral to occupational therapist) (31/41 trials). Medication review (25/41 trials) and psychological interventions (eg, cognitive-behavioural intervention, referral to mental health services) (17/41 trials) were also common (online supplementary appendix 5). Poor reporting for some trials meant that it was not always possible to identify the key components of the intervention. Over half (28/41) of the trials reported assessing adherence to the intervention, most often by monitoring session adherence. However, the extent to which participants within the trials adhered to the individual treatment components of the intervention was unclear. 


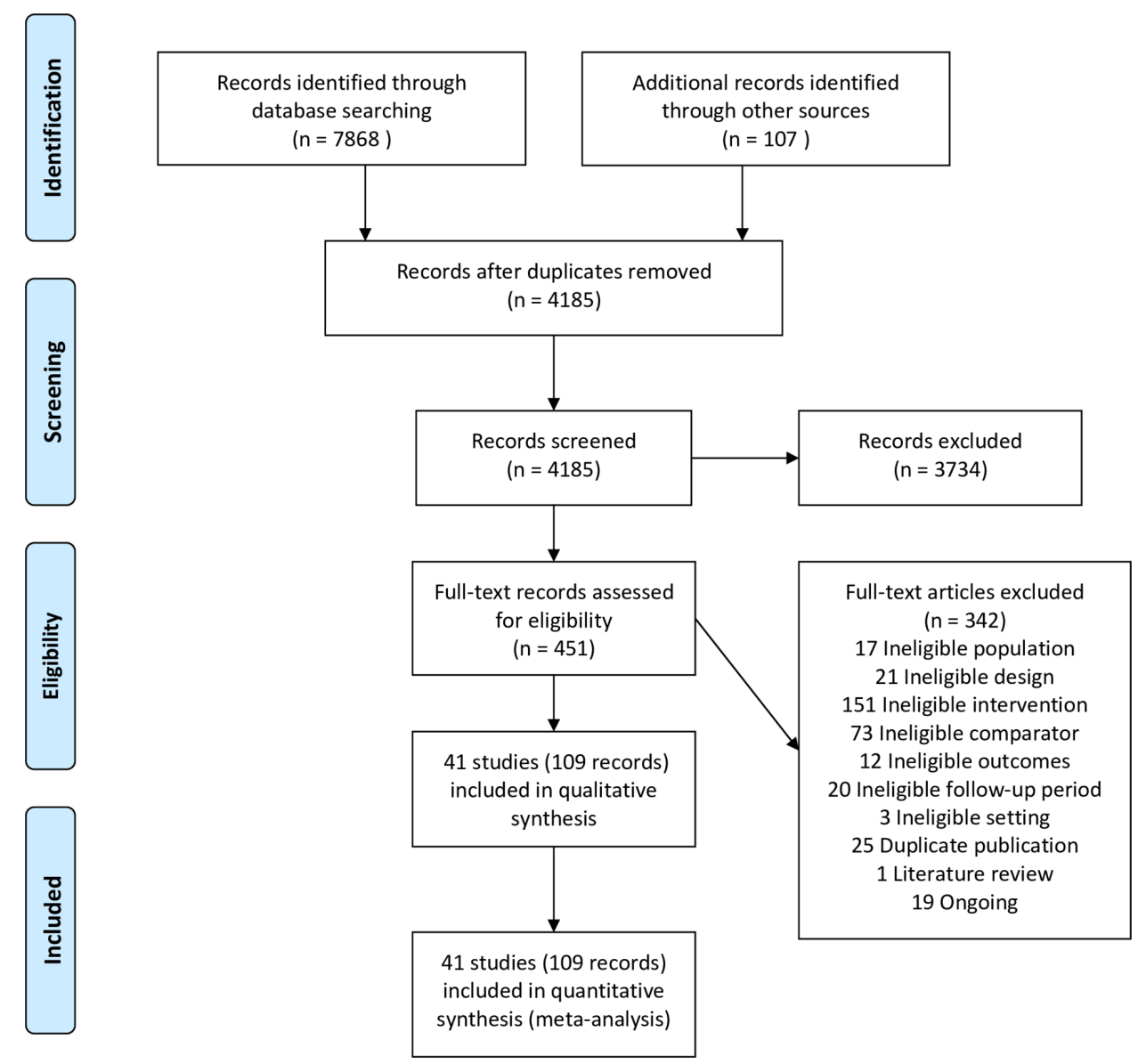

Figure 1 Study flow diagram.

Among the nine registered trials that are not yet published (online supplementary appendix 6), six are likely to have been completed but not yet published, and three are ongoing with completion dates of mid-2019.

\section{Assessment of risk of bias}

The method of sequence generation and concealment of allocation was often unclear (14 and 26 trials, respectively). Blinding of outcome assessment for (1) rate of falls and risk of falling, (2) risk of fractures and (3) requiring hospital admission or medical attention was judged at high risk of bias for 9, 2 and 10 trials, respectively. Fifteen trials reported more than 20\% loss to follow-up. In nine trials there was potential for high risk of bias due to the method of ascertaining falls which was by longer term participant recall, at intervals during the study or at its conclusion. Details of the risk of bias assessment for each trial are summarised in figure 2 (online supplementary appendix 2).

\section{Rate of falls}

Twenty trials ${ }^{29} 31$ 33-36 38-40 42 $444547515557-606264$ provided data on the rate of falls and showed that multifactorial interventions may reduce the rate of falls compared with those who received the comparator intervention (RaR $0.79,95 \% \mathrm{CI} 0.70$ to 0.88 ; 20 trials; 10116 participants; $\mathrm{I}^{2}=90 \%$; low-quality evidence) (figure 3, table 1); however, there was considerable unexplained heterogeneity. Cumulative meta-analysis shows how the effect of multifactorial intervention on reducing the rate of falls has gradually become more conservative over time, as more trials have been conducted (figure 4). The effect remained similar across all strata included in our prespecified subgroup (table 2) and sensitivity analyses (table 3 ) with the exception of the type of comparator intervention. Here multifactorial interventions reduced the rate of falls compared with those who received usual care only ( $\mathrm{RaR} 0.75$, 95\% CI 0.65 to $0.86 ; 15$ trials; 5328 participants; $\left.\mathrm{I}^{2}=90 \%\right)$ but not in the subgroup of trials which were compared with usual care plus advice (RaR $0.90,95 \%$ CI 0.78 to $1.03 ; 5$ trials; 4788 participants; $\left.\mathrm{I}^{2}=81 \%\right)$; this difference was statistically significant at the prespecified $\mathrm{p}<0.1$ level when testing for subgroup differences $\left(\chi^{2}=3.15 ; \mathrm{df}=1 ; \mathrm{p}=0.08 ; \mathrm{I}^{2}=68 \%\right)$.

\section{Risk of falls and risk of recurrent falls}

There may be a small reduction in the risk of people sustaining one or more falls between those people who received multifactorial interventions and those who received the comparator intervention (RR $0.95,95 \%$ CI 0.90 to 1.00 ; 30 trials; 13817 participants; $\mathrm{I}^{2}=56 \%$; moderate-quality evidence) (figures 3 and 4). ${ }^{26-36} 383942-454750-5254-59616264$ There may also be a small reduction in the risk of people sustaining recurrent falls (defined as two or more falls in a specified time period) (RR $0.88,95 \% \mathrm{CI}$ 0.78 to $1.00 ; 15$ trials; 7277 participants; $\mathrm{I}^{2}=46 \%$; moderate-quality evidence) (figure 3). ${ }^{27} 303133-363942485557-5962$ The pooled estimates of effect remained similar in all prespecified subgroup and sensitivity analyses (tables 2 and 3) and were not statistically significant when testing for subgroup differences.

\section{Other fall-related outcomes}

Ten trials 26293033363847505461 provided data on the number of people sustaining one or more fall-related fractures. The pooled 


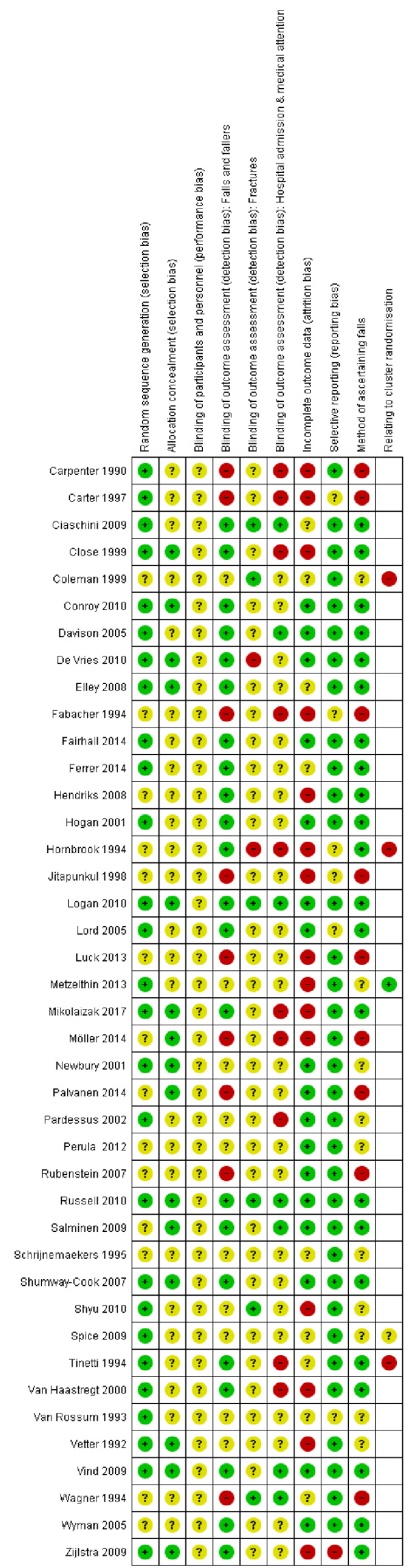

Figure 2 Risk of bias assessment. results showed that multifactorial interventions may make little or no difference on the risk of fall-related fractures compared with the comparator intervention (RR $0.73,95 \%$ CI 0.53 to $1.01 ; 10$ trials; 3160 participants; $\mathrm{I}^{2}=0 \%$; moderate-quality evidence). They may also make little or no difference to the number of people experiencing a fall that required hospital admission (RR $1.00,95 \%$ CI 0.92 to $1.08 ; 14$ trials; 5077 participants; $\mathrm{I}^{2}=0 \%$; low-quality evidence) $)^{242628293236-38454650515356}$ or the risk of experiencing a fall that required medical attention (eg, attended hospital emergency department, required GP consultation) (RR $0.98,95 \%$ CI 0.84 to $1.14 ; 9$ trials; 3669 participants; $\mathrm{I}^{2}=1 \%$; moderate-quality evidence) ${ }^{29} 3536425152555664$ (table 1). It was not always possible to determine that the cause of hospital admission was always due to a fall and we therefore downgraded the level of evidence for this outcome accordingly. Data from seven trials $s^{2733} 3537384660$ showed that multifactorial interventions may also make little or no difference to people's reported health-related quality of life (SMD 0.13, 95\% CI -0.01 to 0.26 ; 7 trials; 2000 participants; low-quality evidence) (table 1; online supplementary appendix 7). When converted to the SF-36 scale ( 0 worst to 100 best), the result indicates a mean difference of 11.84 (95\% CI 0.12 to 30.8 ).

Only three trials reported on adverse events that may have been related to the intervention. One trial reported back pain in two participants, which resolved after modification of the exercise programme ${ }^{33}$; one reported musculoskeletal symptoms in 10 participants, which were 'self-limited' and again probably related to the exercise programme ${ }^{51}$; and one reported there had been no adverse events. ${ }^{57}$

\section{Exploration of impact of trial characteristics on the effect of} multifactorial interventions on falls

The results of the meta-regression are shown in table 5. Overall, heterogeneity remained high and was not explained by the prespecified trial-level characteristics included in the meta-regression. No significant differences were observed for specific trial-level characteristics; this included trials which included usual care only as the comparator intervention, specifically selected people at high risk of falls and those which actively provided treatment to address fall-related risk factors. We were unable to include data on the control rate of falls in the meta-regression as this information was often not reported by the included trials.

\section{Exploration of small study effects}

We found no evidence of potential publication bias $(p<0.1)$ or small study effects (online supplementary appendix 8 ).

\section{DISCUSSION}

\section{Summary of main results}

We identified 41 trials assessing the effects of multifactorial intervention for preventing falls in older people living in the community, with the mean age of participants ranging from 72 to 85 years. The trials included a range of multifactorial interventions, with most trials including at least two or more of the intervention components recommended by NICE. ${ }^{2}$ Exercise-in 35 of 41 trials-was the most common component of multifactorial interventions included in this review with more than half of all trials including study participants judged to be at higher risk of falls at enrolment (ie, participants had either presented for medical attention because of a fall or reported recurrent falls in the past year).

Multifactorial interventions were found to reduce the rate of falls when compared with those who received the comparator 
Effect of multifactorial interventions on rate of falls

\begin{tabular}{|c|c|c|c|c|c|c|c|c|c|}
\hline Study or Subgroup & log[Rate Ratio] & \multicolumn{2}{|r|}{ Multifactorial } & \multicolumn{2}{|l|}{ Control } & $\begin{array}{c}\text { Rate Ratio } \\
\text { IV, Random, } 95 \% \mathrm{Cl}\end{array}$ & \multicolumn{3}{|c|}{$\begin{array}{c}\text { Rate Ratio } \\
\text { IV, Random, } 95 \% \mathrm{Cl}\end{array}$} \\
\hline Conroy 2010 & -0.15 & 0.08 & 172 & 172 & $5.6 \%$ & $0.86[0.74,1.01]$ & $न$ & & \\
\hline Davison 2005 & -0.45 & 0.06 & 144 & 149 & $5.9 \%$ & $0.64[0.57,0.72]$ & - & & \\
\hline Elley 2008 & -0.04 & 0.08 & 155 & 157 & $5.6 \%$ & $0.96[0.82,1.12]$ & & & \\
\hline Fairhall 2014 & 0.11 & 0.19 & 107 & 109 & $3.7 \%$ & $1.12[0.77,1.62]$ & - & & \\
\hline Ferrer 2014 & -0.16 & 0.26 & 142 & 131 & $2.7 \%$ & $0.85[0.51,1.42]$ & & & \\
\hline Hogan 2001 & -0.23 & 0.09 & 75 & 77 & $5.5 \%$ & $0.79[0.67,0.95]$ & $\rightarrow$ & & \\
\hline Hornbrook 1994 & -0.18 & 0.03 & 1611 & 1571 & $6.2 \%$ & $0.84[0.79,0.89]$ & 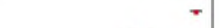 & & \\
\hline Logan 2010 & -0.8 & 0.07 & 98 & 99 & $5.8 \%$ & $0.45[0.39,0.52]$ & - & & \\
\hline Lord 2005 & 0.04 & 0.11 & 192 & 197 & $5.1 \%$ & $1.04[0.84,1.29]$ & & & \\
\hline Luck 2013 & -1.14 & 0.2 & 118 & 112 & $3.5 \%$ & $0.32[0.22,0.47]$ & & & \\
\hline Mikolaizak 2017 & 0.18 & 0.08 & 111 & 110 & $5.6 \%$ & $1.20[1.02,1.40]$ & & - & \\
\hline Möller 2014 & 0.03 & 0.15 & 56 & 50 & $4.4 \%$ & $1.03[0.77,1.38]$ & - & & \\
\hline Palvanen 2014 & -0.32 & 0.05 & 661 & 653 & $6.0 \%$ & $0.73[0.66,0.80]$ & - & & \\
\hline Pardessus 2002 & -0.22 & 0.3 & 30 & 30 & $2.3 \%$ & $0.80[0.45,1.44]$ & & & \\
\hline Russell 2010 & -0.44 & 0.04 & 344 & 354 & $6.1 \%$ & $0.64[0.60,0.70]$ & - & & \\
\hline Salminen 2009 & -0.09 & 0.09 & 292 & 296 & $5.5 \%$ & $0.91[0.77,1.09]$ & & & \\
\hline Shumway-Cook 2007 & -0.29 & 0.08 & 226 & 227 & $5.6 \%$ & $0.75[0.64,0.88]$ & - & & \\
\hline Tinetti 1994 & -0.57 & 0.14 & 147 & 144 & $4.6 \%$ & $0.57[0.43,0.74]$ & - & & \\
\hline Vind 2009 & 0.02 & 0.07 & 196 & 196 & $5.8 \%$ & $1.02[0.89,1.17]$ & & & \\
\hline Zijlstra 2009 & -0.15 & 0.14 & 196 & 209 & $4.6 \%$ & $0.86[0.65,1.13]$ & $\longrightarrow$ & & \\
\hline Total $(95 \% \mathrm{Cl})$ & & & 5073 & 5043 & $100.0 \%$ & $0.79[0.70,0.88]$ & - & & \\
\hline $\begin{array}{l}\text { Heterogeneity: } \operatorname{Tau}^{2}= \\
\text { Test for overall effect: }\end{array}$ & $\begin{array}{l}05 ; \mathrm{Chi}^{2}=197.87, \\
=4.19(\mathrm{P}<0.000\end{array}$ & df $=1$ & $19(P<0.00001$ & $; 1^{2}=90 \%$ & & & $\begin{array}{lr}0.1 & 0.2 \\
& 0.2\end{array}$ & 2 & 10 \\
\hline
\end{tabular}

Effect of multifactorial interventions on risk of sustaining one or more falls

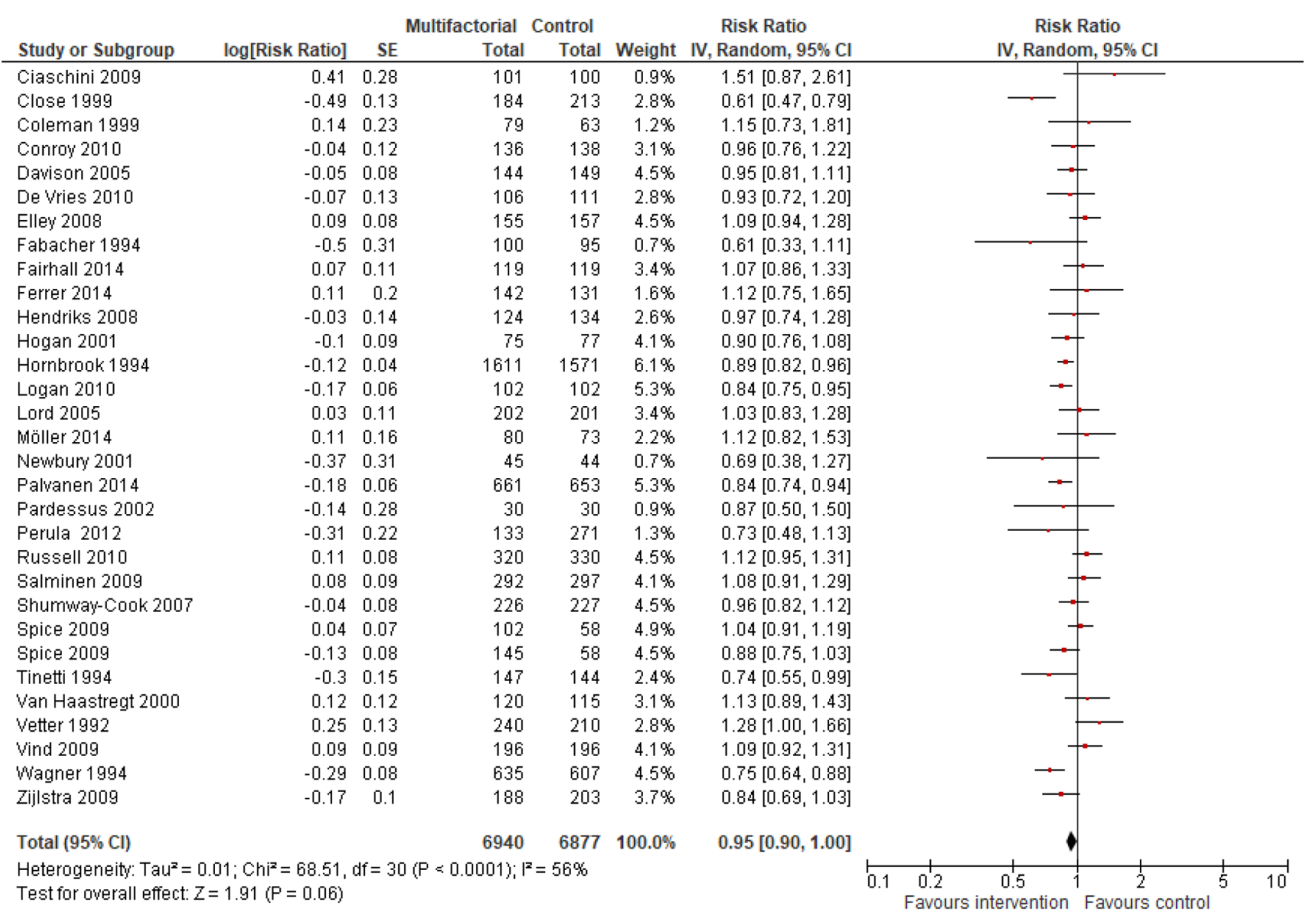

Effect of multifactorial interventions on risk of recurrent falls

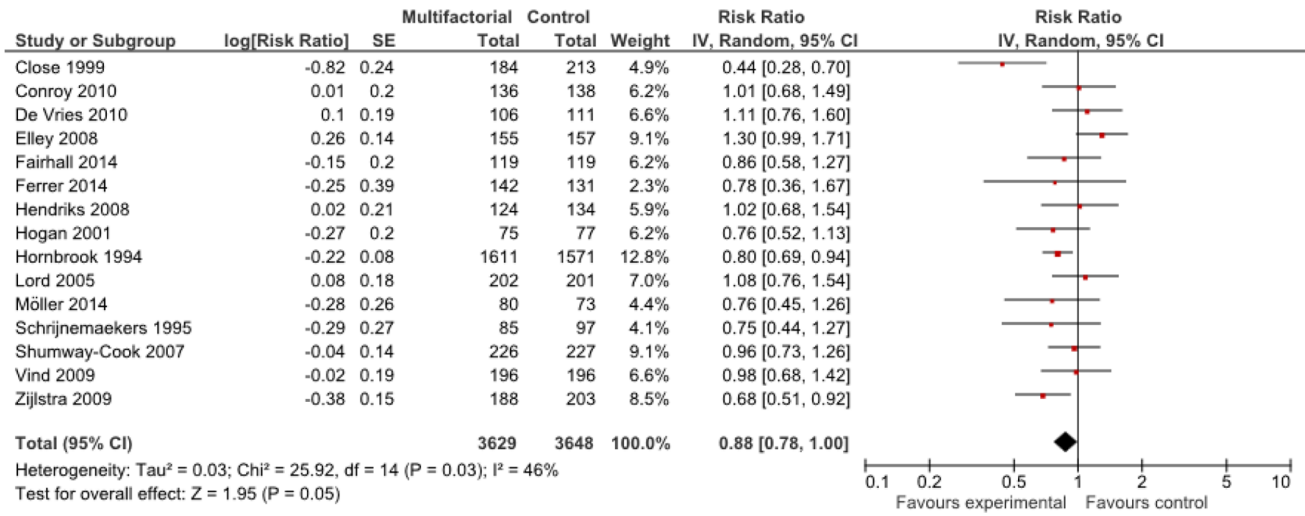

Figure 3 Forest plots for the effect of multifactorial interventions for rate of falls, risk of sustaining one or more falls and risk of recurrent falls. 
Table 1 Effect of multifactorial intervention compared with usual care or usual care plus advice

\begin{tabular}{|c|c|c|c|c|}
\hline \multirow[b]{2}{*}{ Outcome } & \multicolumn{4}{|l|}{ Overall } \\
\hline & Trials, $\mathbf{n}$ & Participants, n & $\begin{array}{l}\text { Effect estimate (random effects) } \\
95 \% \mathrm{Cl}\end{array}$ & $I^{2}(\%)$ \\
\hline Rate of falls & 20 & 10116 & $\operatorname{RaR} 0.79$ (0.70 to 0.88$)$ & 90 \\
\hline Risk of sustaining one or more falls & 30 & 13817 & RR 0.95 (0.90 to 1.00$)$ & 56 \\
\hline Risk of recurrent falls & 15 & 7277 & RR 0.88 (0.78 to 1.00$)$ & 46 \\
\hline Risk of fall-related fractures & 10 & 3160 & RR 0.73 (0.53 to 1.01$)$ & 0 \\
\hline Risk of a fall that required hospital admission & 14 & 5077 & RR 1.00 (0.92 to 1.08$)$ & 0 \\
\hline Risk of a fall that required medical attention & 9 & 3669 & RR 0.98 (0.84 to 1.14$)$ & 1 \\
\hline Health-related quality of life & 7 & 2000 & SMD $0.13(-0.01$ to 0.26$)$ & 52 \\
\hline
\end{tabular}

$\mathrm{RR}$, risk ratio; $\mathrm{RaR}$, rate ratio; $S M D$, standardised mean difference.

intervention; however, there was considerable unexplained heterogeneity. Multifactorial interventions are a specific type of intervention, where their definition means that the individual components of the intervention will differ (based on an individual's risk profile), both within an individual trial and across trials. As such, a certain amount of heterogeneity would be anticipated; however, we have downgraded our confidence in the results to low, reflecting our uncertainty around the treatment effect. Cumulative meta-analysis ${ }^{65}$ shows how the effect of multifactorial interventions on reducing the rate of falls has gradually become more conservative and stable over time, as more trials have been conducted.

Multifactorial interventions may slightly reduce the risk of people sustaining one or more falls and in the risk of recurrent falls. However, for both of these outcomes the 95\% CIs around the treatment effect were quite wide and included a relative risk of 1.00; hence there is uncertainty. Multifactorial interventions may make little or no difference in the risk of other fall-related outcomes (ie, fall-related fractures, falls requiring hospital admission or medical attention, or change in health-related quality of life).

Subgroup analysis demonstrated a difference in the rate of falls in trials where the comparator was usual care but not in trials where the comparator was usual care plus non-tailored falls prevention advice. This suggests that in trials which included a structured falls prevention advice leaflet as the comparator intervention the potential effectiveness of the multifactorial interventions is reduced. The effect of multifactorial interventions on fall outcomes was not influenced by selection of participants at high versus low risk of falls, the inclusion of NICE-recommended components or active versus referral interventions. Sensitivity analyses, excluding trials at high or unclear risk of bias, also showed little or no difference to the overall results. Overall, heterogeneity remained high when assessing the rate of falls and was not explained by the prespecified trial-level characteristics included in the meta-regression.

Previous research has shown that exercises, in particular balance and functional exercises, are an effective and well-established intervention for reducing the rate of falls and fall-related outcomes in older people living in the community. ${ }^{66}$ Our review brings into question the additional benefit and cost associated with the added complexity of a multifactorial intervention programme. Future research is needed to establish a better picture of the added benefit of including other interventions, alongside exercise, as part of a multifactorial intervention in reducing the rate of falls and fall-related injuries.

\section{Comparison with other reviews}

This review builds on the findings from previous systematic reviews with a number of notable differences. The recent Cochrane review ${ }^{12}$ of multifactorial interventions to prevent falls in community-dwelling older people only included trials where the comparator was usual care, whereas our review also included trials where the comparator was usual care plus non-tailored falls prevention advice. We also restricted the inclusion criteria to trials that provided long-term (ie, 12 months' follow-up or longer) follow-up data, to enable a more focused analysis of the sustained effects of interventions. We included meta-regression to investigate between trial variability and the association of intervention and sample characteristics on trial effects.

Several other recent systematic reviews of fall prevention interventions also included meta-analyses of multifactorial interventions. Guirguis-Blake and colleagues conducted a systematic review of fall prevention interventions to inform the US Preventive Services Task Force. ${ }^{16}$ They found that multifactorial interventions were associated with a reduction in the rate of falls (Incidence Rate Ratio 0.79; 95\% CI 0.68 to 0.91 ) but not in other fall-related mobility and mortality outcomes. ${ }^{16}$ A Cochrane review of interventions for preventing falls in older people in care facilities and hospitals ${ }^{67}$ also found evidence that multifactorial interventions may reduce the rate of falls (Rate Ratio $0.80 ; 95 \%$ CI 0.64 to $1.01 ; 5$ trials; 44664 participants) in older people in hospitals but not in the risk of falling. However, there was no difference in the rate of falls and risk of falling between multifactorial interventions and control in older people living in care facilities. Similarly, Tricco and colleagues assessed the effectiveness of interventions for preventing injurious falls and fall-related hospitalisations among both community-dwelling and institutionalised older adults. ${ }^{15}$ They found that multifactorial interventions were associated with a reduction in injurious falls (OR 0.30; $95 \%$ CI 0.13 to 0.70 ) but not fall-related hospitalisation. ${ }^{15}$

\section{Strengths and limitations of this review}

The strengths of this review include the comprehensive search, explicit eligibility criteria, duplicate assessment of eligibility, risk of bias assessment, consideration of possible subgroup effects and rigorous use of the GRADE approach to rate the overall quality of evidence. The interventions assessed in this review are reflective of what patients would receive in clinical practice in the UK, ${ }^{2}$ including the use of usual care plus non-tailored falls prevention advice. The inclusion of meta-regression in addition to meta-analysis allowed us to examine the effect of prespecific trial-level factors on outcomes. 


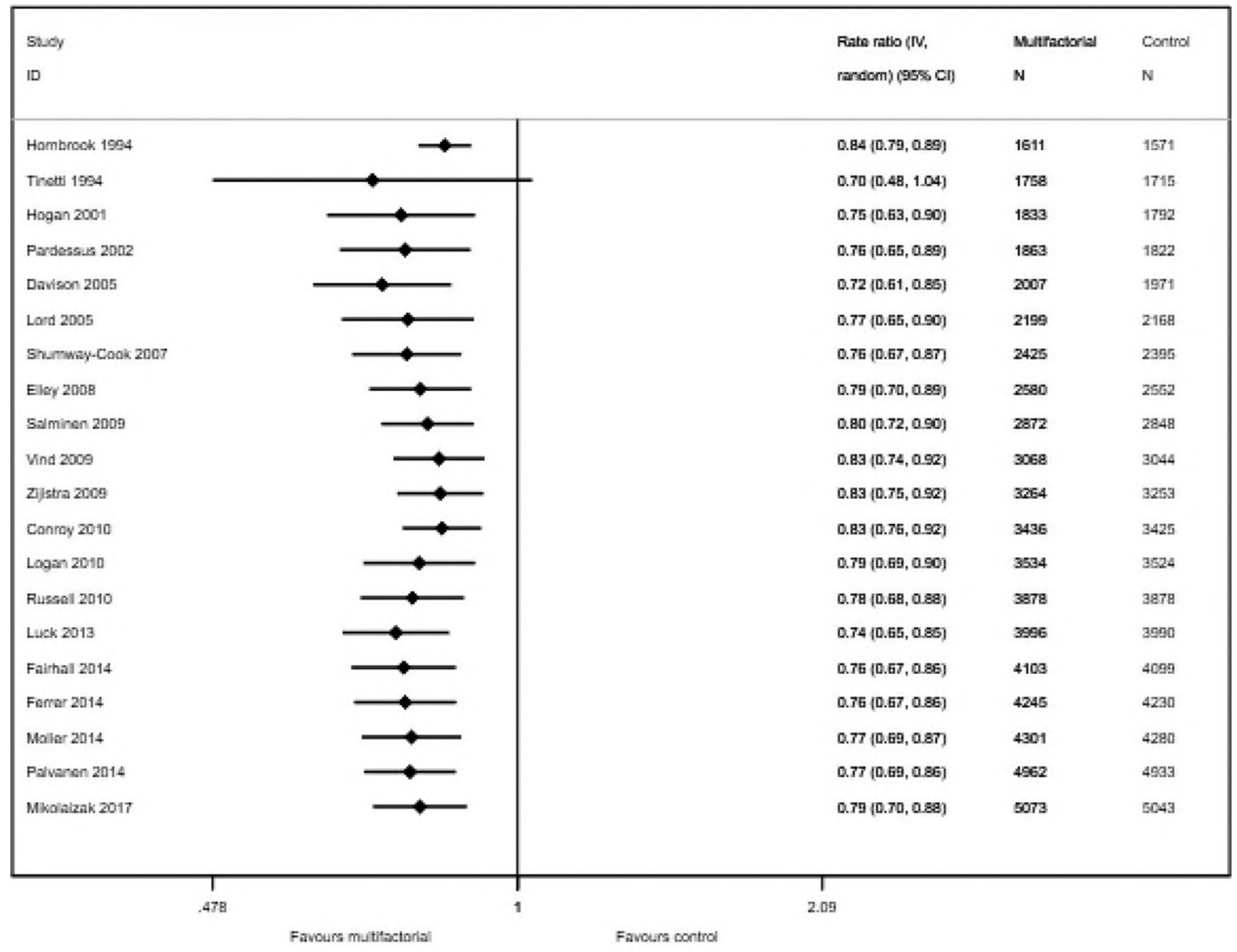

\begin{tabular}{|llllll|}
\hline Sudty \\
ID
\end{tabular}

Figure 4 Cumulative meta-analysis for the effect of multifactorial interventions on rate of falls and risk of sustaining one or more falls. 
Table 2 Subgroup analyses for the effect of multifactorial intervention on rate of falls and risk of sustaining one or more falls and recurrent falls

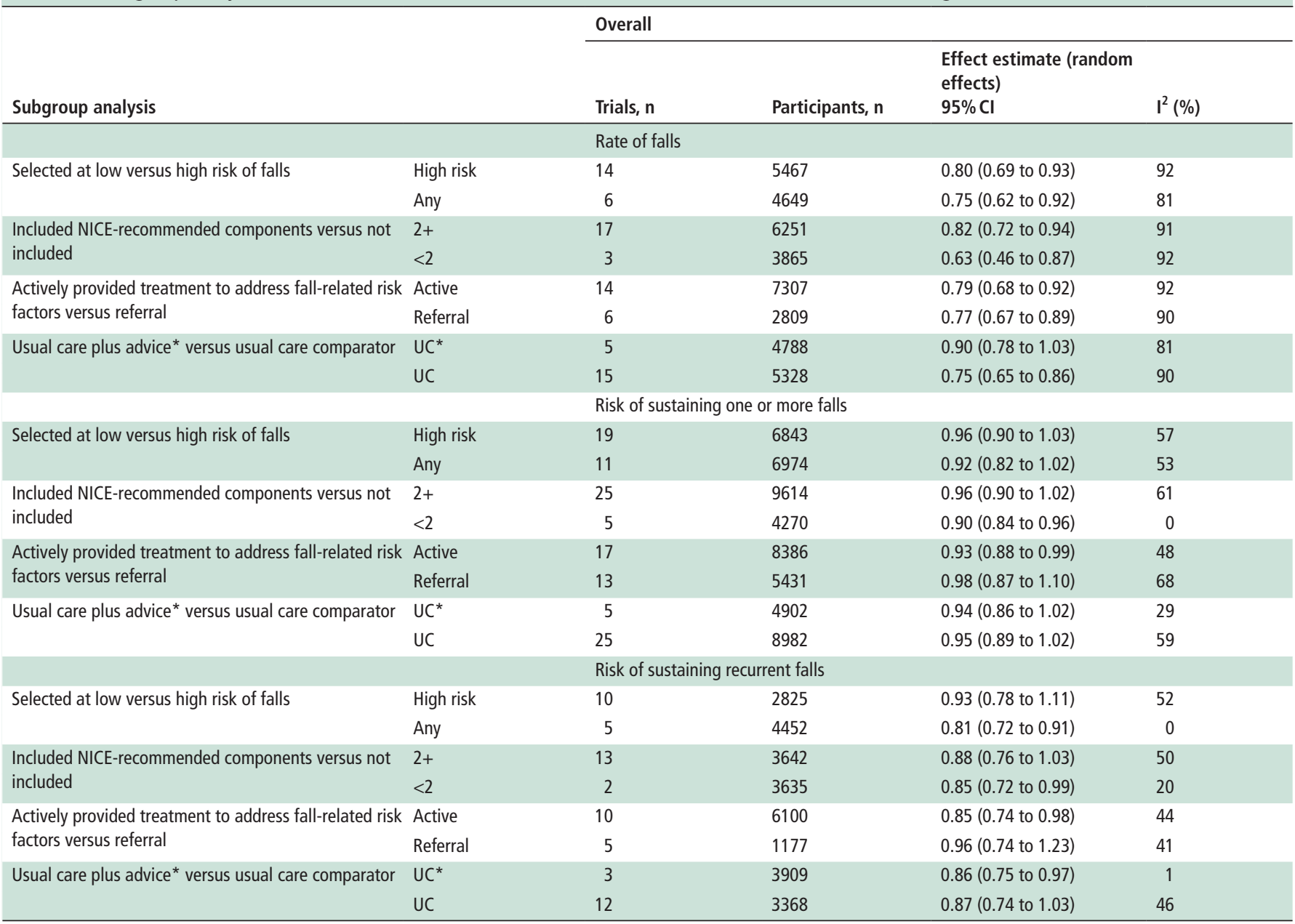

*Usual care and usual care plus non-tailored falls prevention advice in either written, audio or visual material format.

NICE, National Institute for Health and Care Excellence; UC, usual care.

Table 3 Sensitivity analyses for the effect of multifactorial intervention on rate of falls and risk of sustaining one or more falls and recurrent falls

\begin{tabular}{|c|c|c|c|c|}
\hline \multirow[b]{2}{*}{ Sensitivity analysis } & \multicolumn{4}{|l|}{ Overall } \\
\hline & Trials, $\mathrm{n}$ & Participants, n & $\begin{array}{l}\text { Effect estimate (random } \\
\text { effects) } 95 \% \mathrm{Cl}\end{array}$ & $I^{2}(\%)$ \\
\hline & \multicolumn{4}{|c|}{ Rate of falls } \\
\hline Adequate concealment of allocation & 10 & 4442 & $0.82(0.68$ to 0.97$)$ & 94 \\
\hline Adequate blinding of outcome assessors & 15 & 8062 & 0.81 (0.71 to 0.92$)$ & 92 \\
\hline Adequate handling of incomplete outcome data* & 12 & 5096 & 0.78 (0.68 to 0.89$)$ & 90 \\
\hline Adequate concealment of allocation & 13 & 5296 & 0.95 (0.86 to 1.04$)$ & 69 \\
\hline Adequate blinding of outcome assessors & 18 & 8481 & 0.95 (0.89 to 1.02$)$ & 54 \\
\hline Adequate handling of incomplete outcome data* & 15 & 5732 & 0.96 (0.90 to 1.02$)$ & 36 \\
\hline Individual randomisation & 26 & 9839 & 0.95 (0.89 to 1.02$)$ & 59 \\
\hline \multicolumn{5}{|c|}{ Risk of sustaining recurrent falls } \\
\hline
\end{tabular}


Table 4 Multifactorial intervention compared with usual care or usual care plus advice for preventing falls in older people living in the community

Patient or population: Preventing falls in older people living in the community

Setting: Older people living in the community

Intervention: Multifactorial intervention

Comparison: Usual care or usual care plus minimal control

\begin{tabular}{|c|c|c|c|c|c|c|}
\hline \multirow[b]{2}{*}{ Outcomes } & \multicolumn{2}{|c|}{ Anticipated absolute effects* $(95 \% \mathrm{Cl})$} & \multirow[b]{2}{*}{$\begin{array}{l}\text { Relative effect } \\
(95 \% \mathrm{Cl})\end{array}$} & \multirow[b]{2}{*}{$\begin{array}{l}\text { Number of } \\
\text { participants } \\
\text { (studies) }\end{array}$} & \multirow[b]{2}{*}{$\begin{array}{l}\text { Certainty of the } \\
\text { evidence } \\
\text { (GRADE) }\end{array}$} & \multirow[b]{2}{*}{ Comments } \\
\hline & $\begin{array}{l}\text { Risk with } \\
\text { comparator } \\
\text { intervention }\end{array}$ & $\begin{array}{l}\text { Risk with } \\
\text { multifactorial } \\
\text { intervention }\end{array}$ & & & & \\
\hline $\begin{array}{l}\text { Rate of falls (falls per person-years) } \\
\text { Follow-up: range } 12-24 \text { months }\end{array}$ & 1416 per 1000 & $\begin{array}{l}1119 \text { per } 1000 \\
\text { (991 to 1246) }\end{array}$ & $\begin{array}{l}\text { Rate ratio } 0.79 \\
(0.70 \text { to } 0.88)\end{array}$ & $\begin{array}{l}10116 \\
\text { (20 RCTs) }\end{array}$ & $\begin{array}{l}\oplus \oplus \bigcirc \bigcirc \\
\text { Lowt‡ }\end{array}$ & \\
\hline $\begin{array}{l}\text { Number of people sustaining one or more } \\
\text { falls } \\
\text { Follow-up: range } 12-48 \text { months }\end{array}$ & 467 per 1000 & $\begin{array}{l}444 \text { per } 1000 \\
(421 \text { to } 467)\end{array}$ & $\begin{array}{l}R R 0.95 \\
(0.90 \text { to } 1.00)\end{array}$ & $\begin{array}{l}13817 \\
\text { (30 RCTs) }\end{array}$ & $\begin{array}{l}\oplus \oplus \oplus \bigcirc \\
\text { Moderate† }\end{array}$ & \\
\hline $\begin{array}{l}\text { Number of people sustaining recurrent falls } \\
\text { (defined as two or more falls in a specified } \\
\text { time period) } \\
\text { Follow-up: range } 12-24 \text { months }\end{array}$ & 247 per 1000 & $\begin{array}{l}217 \text { per } 1000 \\
\text { (192 to } 247)\end{array}$ & $\begin{array}{l}R R 0.88 \\
(0.78 \text { to } 1.00)\end{array}$ & $\begin{array}{l}7277 \\
\text { (15 RCTs) }\end{array}$ & $\begin{array}{l}\oplus \oplus \oplus \bigcirc \\
\text { Moderate† }\end{array}$ & \\
\hline $\begin{array}{l}\text { Number of people sustaining one or more } \\
\text { fall-related fractures } \\
\text { Follow-up: range } 12-48 \text { months }\end{array}$ & 53 per 1000 & $\begin{array}{l}39 \text { per } 1000 \\
\text { (28 to } 54)\end{array}$ & $\begin{array}{l}R R 0.73 \\
(0.53 \text { to } 1.01)\end{array}$ & $\begin{array}{l}3160 \\
(10 \mathrm{RCTs})\end{array}$ & $\begin{array}{l}\oplus \oplus \oplus \bigcirc \\
\text { Moderate† }\end{array}$ & \\
\hline $\begin{array}{l}\text { Number of people who experience a fall that } \\
\text { required hospital admission } \\
\text { Follow-up: range } 12-36 \text { months }\end{array}$ & 265 per 1000 & $\begin{array}{l}265 \text { per } 1000 \\
\text { (244 to } 286)\end{array}$ & $\begin{array}{l}R R 1.00 \\
\text { (0.92 to } 1.08)\end{array}$ & $\begin{array}{l}5077 \\
(14 \text { RCTs) }\end{array}$ & $\begin{array}{l}\oplus \oplus \bigcirc \bigcirc \\
\text { Lowt§ }\end{array}$ & \\
\hline $\begin{array}{l}\text { Number of people who experience a fall that } \\
\text { required medical attention } \\
\text { Follow-up: range } 12-36 \text { months }\end{array}$ & 151 per 1000 & $\begin{array}{l}148 \text { per } 1000 \\
(127 \text { to } 172)\end{array}$ & $\begin{array}{l}R R 0.98 \\
(0.84 \text { to } 1.14)\end{array}$ & $\begin{array}{l}3669 \\
(9 \text { RCTs })\end{array}$ & $\begin{array}{l}\oplus \oplus \oplus \bigcirc \\
\text { Moderate† }\end{array}$ & \\
\hline $\begin{array}{l}\text { Health-related quality of life: endpoint score } \\
\text { ollow-up: range } 12-36 \text { months }\end{array}$ & - & $\begin{array}{l}\text { SMD } 0.13 \text { higher } \\
\text { (0.01 lower to } 0.26 \\
\text { higher) }\end{array}$ & - & $\begin{array}{l}2000 \\
\text { (7 RCTs) }\end{array}$ & $\begin{array}{l}\oplus \oplus \bigcirc \bigcirc \\
\text { Lowt9 }\end{array}$ & $\begin{array}{l}\text { Converted to SF-36 } \\
\text { scale ( } 0 \text { worst to } \\
100 \text { best) } \\
\text { MD } 11.84 \text { ( } 95 \% \text { Cl } \\
-0.12 \text { to } 30.8)\end{array}$ \\
\hline
\end{tabular}

GRADE Working Group grades of evidence. High certainty: We are very confident that the true effect lies close to that of the estimate of the effect. Moderate certainty: We are moderately confident in the effect estimate. The true effect is likely to be close to the estimate of the effect, but there is a possibility that it is substantially different. Low certainty: Our confidence in the effect estimate is limited. The true effect may be substantially different from the estimate of the effect. Very low certainty: We have very little confidence in the effect estimate. The true effect is likely to be substantially different from the estimate of effect.

${ }^{*}$ The risk in the intervention group (and its $95 \% \mathrm{Cl}$ ) is based on the assumed risk in the comparison group and the relative effect of the intervention (and its $95 \% \mathrm{Cl}$ ). tDowngraded one level for risk of bias (more than one trial at high or unclear risk of bias).

¥Downgraded one level for inconsistency (there was considerable statistical heterogeneity in these outcomes that could not be explained by prespecified sensitivity and subgroup analyses).

§owngraded one level for indirectness (poor reporting meant that it was sometimes unclear how many hospital admissions were falls related; therefore, we included outcome data on hospital admissions in general).

IDowngraded one level for imprecision (relatively broad overall Cl).

GRADE, Grading of Recommendations, Assessment, Development and Evaluation; MD, mean difference; RCT, randomised controlled trial; RR, risk ratio; SMD, standardised mean difference.

The limitations of our review relate largely to the underlying evidence. Trials were heterogeneous $\left(\mathrm{I}^{2}=90 \%\right.$ for rate of falls), meaning results need to be interpreted cautiously. While multifactorial interventions are by their nature heterogeneous, the influence of differences between the included trials must be considered. Several of the subgroups analysed included a small number of studies, limiting the power of these analyses. Egger's tests showed no clear evidence of small study effects; however, we cannot exclude the possibility that trials did not report outcomes for which no positive effect was found. Only 3 of the 41 included trials reported on adverse events. More complete data on adverse outcomes related to multifactorial interventions would improve our ability to judge the overall benefit of these interventions. Our risk of bias assessment identified that improvements are needed in reporting of trials, and measurement of outcomes remains an area of concern. These deficiencies in reporting preclude clinicians and researchers from reliably replicating or implementing interventions.

\section{CONCLUSION AND RECOMMENDATIONS}

Despite current guideline recommendations promoting the use of multifactorial interventions for preventing falls in older people living in the community, the results of our systematic review show that while multifactorial interventions may reduce the rate of falls and slightly reduce risk of people sustaining one or more falls and recurrent falls, they may make little or no difference to other fall-related outcomes (such as fall-related fractures, falls requiring hospital admission or medical attention, health-related quality of life). There is some evidence to suggest that the effect of multifactorial interventions in reducing the rate of falls may be smaller when compared with usual care plus non-tailored falls prevention advice (in either written, audio or visual format) as opposed to usual care only (ie, no change in usual activities).

Contributors SH was involved in screening, data extraction and data analysis, led the writing of the review and acts as the guarantor of the review. BC, PN, GB and 
Table 5 Meta-regression exploring the impact of trial-level characteristics on the effects ${ }^{*}$ of the intervention on the rate of falls and risk of one or more falls and risk of recurrent falls

\begin{tabular}{|c|c|c|c|}
\hline Variable tested in meta-regression & Trials, $\mathrm{n}$ & Coefficient $(95 \% \mathrm{Cl})$ & Reduction in $\mathrm{I}^{2}(\%)$ \\
\hline \multicolumn{4}{|l|}{ Rate of falls $\left(I^{2}\right.$ in original meta-analysis $\left.=90.1 \%\right)$} \\
\hline \multicolumn{4}{|l|}{ Trial design } \\
\hline Sample size & $20 / 20$ & $1.00(1.00$ to 1.00$)$ & -0.2 \\
\hline Less than $20 \%$ missing outcome data & $12 / 20$ & 1.03 (0.68 to 1.54$)$ & 0.7 \\
\hline Comparator usual care only & $15 / 20$ & $0.66(0.42$ to 1.05$)$ & 0.6 \\
\hline \multicolumn{4}{|l|}{ Participant characteristics } \\
\hline Average age $>75$ years & $14 / 20$ & $1.11(0.72$ to 1.69$)$ & -0.5 \\
\hline Selected as high risk of falls & $14 / 20$ & $0.89(0.34$ to 2.33$)$ & -0.1 \\
\hline \multicolumn{4}{|l|}{ Intervention components } \\
\hline Included NICE-recommended components & $17 / 20$ & 2.37 (1.01 to 5.56$)$ & 0.2 \\
\hline Actively provided treatment to address fall-related risk factors & $14 / 20$ & $0.95(0.63$ to 1.45$)$ & -0.8 \\
\hline Adherence was assessed & $15 / 20$ & 0.82 (0.28 to 2.44$)$ & -0.8 \\
\hline \multicolumn{4}{|c|}{ Risk of sustaining one or more falls $\left(\mathrm{I}^{2}\right.$ in original meta-analysis $\left.=55.8 \%\right)$} \\
\hline \multicolumn{4}{|l|}{ Trial design } \\
\hline Sample sizet & $30 / 30$ & $1.00(1.00$ to 1.00$)$ & 1.3 \\
\hline Less than $20 \%$ missing outcome data & $15 / 30$ & 0.98 (0.83 to 1.17$)$ & -1.5 \\
\hline Comparator usual care only & $25 / 30$ & $0.94(0.69$ to 1.26$)$ & 0.1 \\
\hline \multicolumn{4}{|l|}{ Participant characteristics } \\
\hline Average age $>75$ years & $20 / 30$ & $0.96(0.79$ to 1.16$)$ & -0.7 \\
\hline Selected as high risk of falls & $19 / 30$ & $0.89(0.51$ to 1.56$)$ & -0.6 \\
\hline \multicolumn{4}{|l|}{ Intervention components } \\
\hline Included NICE-recommended components & $25 / 30$ & $0.98(0.67$ to 1.44$)$ & -1.3 \\
\hline Actively provided treatment to address fall-related risk factors & $17 / 30$ & $0.94(0.80$ to 1.11$)$ & -0.2 \\
\hline Adherence was assessed & $20 / 30$ & $1.19(0.67$ to 2.13$)$ & -1.0 \\
\hline \multicolumn{4}{|c|}{ Risk of sustaining recurrent falls $\left(\mathrm{I}^{2}\right.$ in original meta-analysis $\left.=46.0 \%\right)$} \\
\hline \multicolumn{4}{|l|}{ Trial design } \\
\hline Sample sizet & $15 / 15$ & $1.00(1.00$ to 1.00$)$ & 0.6 \\
\hline Less than $20 \%$ missing outcome data & $7 / 15$ & $1.31(0.66$ to 2.60$)$ & -0.7 \\
\hline Comparator usual care only & $12 / 15$ & $0.94(0.34$ to 2.59$)$ & -4.4 \\
\hline \multicolumn{4}{|l|}{ Participant characteristics } \\
\hline Average age $>75$ years & $10 / 15$ & $0.94(0.52$ to 1.72$)$ & -4.2 \\
\hline Selected as high risk of falls & $10 / 15$ & $1.13(0.33$ to 3.95$)$ & 1.1 \\
\hline \multicolumn{4}{|l|}{ Intervention components } \\
\hline Included NICE-recommended components & $13 / 15$ & $1.01(0.18$ to 5.46$)$ & -4.1 \\
\hline Actively provided treatment to address fall-related risk factors & $10 / 15$ & $0.78(0.39$ to 1.56$)$ & -1.0 \\
\hline Adherence was assessed & $11 / 15$ & 0.89 (0.19 to 4.06$)$ & -6.8 \\
\hline
\end{tabular}

${ }^{*}$ Associated with a greater fall prevention effect.

tIncluded as continuous variable.

NICE, National Institute for Health and Care Excellence.

BA were involved in screening, data extraction and data analysis, and contributed to writing of the review. SL conceived the study idea, gained funding, interpreted the data analysis and contributed to writing of the review.

Funding This research is supported by the National Institute for Health Research (NIHR) Collaboration for Leadership in Applied Health Research and Care Oxford at Oxford Health NHS Foundation Trust, and the NIHR Oxford Musculoskeletal Biomedical Research Unit.

Disclaimer The views expressed in this publication are those of the authors and not necessarily those of the NHS, the NIHR or the Department of Health.

Competing interests None declared.

Patient consent for publication Not required.

Provenance and peer review Not commissioned; externally peer reviewed.

Open access This is an open access article distributed in accordance with the Creative Commons Attribution Non Commercial (CC BY-NC 4.0) license, which permits others to distribute, remix, adapt, build upon this work non-commercially, and license their derivative works on different terms, provided the original work is properly cited, appropriate credit is given, any changes made indicated, and the use is non-commercial. See: http://creativecommons.org/licenses/by-nc/4.0/.

\section{REFERENCES}

1 Campbell AJ, Robertson MC. Implementation of multifactorial interventions for fall and fracture prevention. Age Ageing 2006;35(suppl_2):ii60-4.

2 Excellence NIfHaC. Falls in older people: assessing risk and prevention 2013 [CG161] 2016. Available: wwwniceorguk/guidance/cg161/chapter/1-recommendations

3 Peel NM, Kassulke DJ, McClure RJ. Population based study of hospitalised fall related injuries in older people. Injury Prevention 2002;8:280-3.

4 Campbell AJ, Borrie MJ, Spears GF, et al. Circumstances and consequences of falls experienced by a community population 70 years and over during a prospective study. Age Ageing 1990;19:136-41.

5 Tinetti ME, Speechley M, Ginter SF. Risk factors for falls among elderly persons living in the community. N Engl I Med 1988;319:1701-7.

6 Scuffham P, Chaplin S, Legood R. Incidence and costs of unintentional falls in older people in the United Kingdom. J Epidemiol Community Health 2003;57:740-4.

7 Deandrea S, Lucenteforte E, Bravi F, et al. Risk factors for falls in community-dwelling older people: a systematic review and meta-analysis. Epidemiology 2010;21:658-68. 
8 Todd C, Skelton D. What are the main risk factors for falls among older people and what are the most effective interventions to prevent these falls? March 2004. Copenhagen, who regional office for Europe (health evidence network report), 2016. Available: wwweurowhoint/document/E82552pdf

9 Australian Commission on S, quality in healthcare. preventing falls and harm from falls in older people. Best Practice Guidelines for Australian Community Care 2016;2009 wwwsafetyandqualitygovau/wp-content/uploads/2012/01/Guidelines-COMMpdf

10 Panel on prevention of falls in older persons AGSaBGS. summary of the updated American geriatrics Society/British geriatrics Society clinical practice guideline for prevention of falls in older persons. J Am Geriatr Soc 2011;59:148-57.

11 Lamb SE, Becker C, Gillespie LD, et al. Reporting of complex interventions in clinical trials: development of a taxonomy to classify and describe fall-prevention interventions. Trials 2011;12:125-25.

12 Hopewell S, Adedire O, Copsey BJ, et al. Multifactorial and multiple component interventions for preventing falls in older people living in the community. Cochrane Database of Systematic Reviews 2018;32.

13 Gillespie LD, Robertson MC, Gillespie WJ, et al. Interventions for preventing falls in older people living in the community. Cochrane Database of Systematic Reviews 2012;85.

14 Gates S, Fisher JD, Cooke MW, et al. Multifactorial assessment and targeted intervention for preventing falls and injuries among older people in community and emergency care settings: systematic review and meta-analysis. BMJ 2008:336:130-3.

15 Tricco AC, Thomas SM, Veroniki AA, et al. Comparisons of interventions for preventing falls in older adults: a systematic review and meta-analysis. Jama 2017:318:1687-99.

16 Guirguis-Blake JM, Michael YL, Perdue LA, et al. Interventions to prevent falls in older adults: updated evidence report and systematic review for the US preventive services Task force. Jama 2018;319:1705-16.

17 Excellence NIfHaC. Developing NICE guidelines: the manual. Chapter 7: incorporating economic evaluation, 2015. Available: https:/wwwniceorguk/process/pmg20/chapter/ incorporating-economic-evaluation [Accessed 11 Dec 2018]

18 Lamb SE, Jørstad-Stein EC, Hauer K, et al. Development of a common outcome data set for fall injury prevention trials: the prevention of falls network Europe consensus. J Am Geriatr Soc 2005;53:1618-22.

19 Higgins JPT, Green S. Cochrane Handbook of Systematic Reviews of Interventions Version 5.1.0. The Cochrane Collaboration, 2011. Available: wwwcochranehandbookorg [Accessed Mar 2011].

20 Griffin J, Lall R, Bruce J, et al. Comparison of alternative falls data collection methods in the prevention of falls injury trial (PreFIT). J Clin Epidemiol 2019;106:32-40.

21 Schünemann HJ, Oxman AD, Higgins JPT, et al. Chapter 11: Presenting results and 'Summary of findings' tables. In: Higgins JPT, Green S, eds. Cochrane Handbook for Systematic Reviews of Interventions Version 5.1.0 [updated March 2011]. The Cochrane Collaboration, 2011

22 Smeeth L, Ng ES-W. Intraclass correlation coefficients for cluster randomized trials in primary care: data from the MRC trial of the assessment and management of older people in the community. Control Clin Trials 2002;23:409-21.

23 Group DJHJADobotCSM. Identifying and measuring hetergeneity [Chapter 9; Section 9.5.2]. Cochrane Handbook of Systematic Reviews of Interventions $2018 \mathrm{https}: / /$ handbook-5-1.cochrane.org/chapter_9/9_5_2_identifying_and_measuring_ heterogeneity.htm (accessed 19 December 2018).

24 Carpenter Gl, Demopoulos GR. Screening the elderly in the community: controlled trial of dependency surveillance using a questionnaire administered by volunteers. BMJ 1990;300:1253-6.

25 Carter SCE, Sanson-Fisher R, Tiller K, et al. Trial data (as supplied 1997). data on file 1997.

26 Ciaschini PM, Straus SE, Dolovich LR, et al. Community-Based intervention to optimise falls risk management: a randomised controlled trial. Age Ageing 2009;38:724-30.

27 Close J, Ellis M, Hooper R, et al. Prevention of falls in the elderly trial (PROFET): a randomised controlled trial. The Lancet 1999;353:93-7.

28 Coleman EA, Grothaus LC, Sandhu N, et al. Chronic care clinics: a randomized controlled trial of a new model of primary care for frail older adults. J Am Geriatr Soc 1999;47:775-83.

29 Davison J, Bond J, Dawson P, et al. Patients with recurrent falls attending Accident \& Emergency benefit from multifactorial intervention —a randomised controlled trial. Age Ageing 2005;34:162-8

30 de Vries OJ, Peeters GMEEG, Elders PJM, et al. Multifactorial intervention to reduce falls in older people at high risk of recurrent falls: a randomized controlled trial. Arch Intern Med 2010;170:1110-7.

31 Elley CR, Robertson MC, Garrett S, et al. Effectiveness of a falls-and-fracture nurse coordinator to reduce falls: a randomized, controlled trial of at-risk older adults. J Am Geriatr Soc 2008;56:1383-9.

32 Fabacher D, Josephson K, Pietruszka F, et al. An in-home preventive assessment program for independent older adults: a randomized controlled trial. J Am Geriatr Soc 1994:42:630-8

33 Fairhall N, Sherrington C, Lord SR, et al. Effect of a multifactorial, interdisciplinary intervention on risk factors for falls and fall rate in frail older people: a randomised controlled trial. Age Ageing 2014;43:616-22.
34 Ferrer A, Formiga F, Sanz H, et al. Multifactorial assessment and targeted intervention to reduce falls among the oldest-old: a randomized controlled trial. Clin Interv Aging 2014;9:383-94.

35 Hendriks MRC, Evers SMAA, Bleiilevens MHC, et al. Cost-Effectiveness of a multidisciplinary fall prevention program in community-dwelling elderly people: a randomized controlled trial (ISRCTN 64716113). Int J Technol Assess Health Care 2008;24:193-202.

36 Hogan D, MacDonald F, Betts J, et al. A randomized controlled trial of a communitybased consultation service to prevent falls. CMAJ 2001;165:537-43.

37 Jitapunkul S. A randomised controlled trial of regular surveillance in Thai elderly using a simple questionnaire administered by non-professional personnel. J Med Assoc Thai 1998:81:352-6.

38 Logan PA, Coupland CAC, Gladman JRF, et al. Community falls prevention for people who call an emergency ambulance after a fall: randomised controlled trial. BMJ 2010;340.

39 Lord SR, Tiedemann A, Chapman K, et al. The effect of an individualized fall prevention program on fall risk and falls in older people: a randomized, controlled trial. J Am Geriatr Soc 2005;53:1296-304.

40 Luck T, Motzek T, Luppa M, et al. Effectiveness of preventive home visits in reducing the risk of falls in old age: a randomized controlled trial. Clin Interv Aging 2013;8:697-702

41 Metzelthin SF, van Rossum E, de Witte LP, et al. Effectiveness of interdisciplinary primary care approach to reduce disability in community dwelling frail older people: Cluster randomised controlled trial. In: BMJ (Clinical Research). 2013: 347, f5264.

42 Möller UO, Kristensson J, Midlöv P, et al. Effects of a one-year home-based case management intervention on falls in older people: a randomized controlled trial. $J$ Aging Phys Act 2014;22:457-64.

43 Newbury JW, Marley JE, Beilby JJ. A randomised controlled trial of the outcome of health assessment of people aged 75 years and over. Med J Aust 2001;175:104-7.

44 Palvanen M, Kannus P, Piirtola M, et al. Effectiveness of the chaos falls clinic in preventing falls and injuries of home-dwelling older adults: a randomised controlled trial. Injury 2014;45:265-71.

45 Pardessus V, Puisieux F, Di Pompeo C, Di P, et al. Benefits of home visits for falls and autonomy in the elderly: a randomized trial study. Am J Phys Med Rehabil 2002;81.

46 Rubenstein LZ, Alessi CA, Josephson KR, et al. A randomized trial of a screening, case finding, and referral system for older veterans in primary care. J Am Geriatr Soc 2007; 55:166-74

47 Russell MA, Hill KD, Day LM, et al. A randomized controlled trial of a multifactorial falls prevention intervention for older fallers presenting to emergency departments. J Am Geriatr Soc 2010;58:2265-74.

48 Schrijnemaekers VJ, Haveman MJ. Effects of preventive outpatient geriatric assessment: short-term results of a randomized controlled study. Home Health Care Serv 0 1995:15:81-97.

49 Shyu Y-IL, Liang J, Wu C-C, et al. An interdisciplinary intervention for older Taiwanese patients after surgery for hip fracture improves health-related quality of life. $B M C$ Musculoskelet Disord 2010;11:225

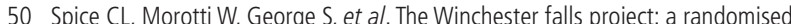
controlled trial of secondary prevention of falls in older people. Age Ageing 2009:38:33-40.

51 Tinetti ME, Baker DI, McAvay G, et al. A multifactorial intervention to reduce the risk of falling among elderly people living in the community. N Eng/ I Med 1994:331:821-7.

52 van Haastregt JCMet al. Effects of a programme of multifactorial home visits on falls and mobility impairments in elderly people at risk: randomised controlled trial. BMJ 2000;321:994-8

53 van Rossum E, Frederiks CM, Philipsen $\mathrm{H}$, et al. Effects of preventive home visits to elderly people. BMJ 1993;307:27-32.

54 Vetter NJ, Lewis PA, Ford D. Can health visitors prevent fractures in elderly people? BMJ 1992;304:888-90.

55 Vind $A B$, Andersen $H E$, Pedersen $K D$, et al. An outpatient multifactorial falls prevention intervention does not reduce falls in high-risk elderly Danes. J Am Geriatr Soc 2009:57:971-7.

56 Wagner EH, LaCroix AZ, Grothaus L, et al. Preventing disability and falls in older adults: a population-based randomized trial. Am J Public Health 1994;84:1800-6.

57 Zijlstra GAR, Van Haastregt JCM, Ambergen T, et al. Effects of a multicomponent cognitive behavioral group intervention on fear of falling and activity avoidance in community-dwelling older adults: results of a randomized controlled trial. J Am Geriatr Soc 2009;57:2020-8.

58 Conroy S, Kendrick D, Harwood R, et al. A multicentre randomised controlled trial of day hospital-based falls prevention programme for a screened population of community-dwelling older people at high risk of falls. Age Ageing 2010;39:704-10.

59 Hornbrook MC, Stevens VJ, Wingfield DJ, et al. Preventing falls among communitydwelling older persons: results from a randomized trial. Gerontologist 1994;34:16-23.

60 Mikolaizak AS, Lord SR, Tiedemann A, et al. A multidisciplinary intervention to prevent subsequent falls and health service use following fall-related paramedic care: a randomised controlled trial. Age Ageing 2017;46:200-7. 
61 Pérula LA, Varas-Fabra F, Rodríguez V, et al. Effectiveness of a multifactorial intervention program to reduce falls incidence among community-living older adults: a randomized controlled trial. Arch Phys Med Rehabil 2012;93:1677-84.

62 Shumway-Cook A, Silver IF, LeMier M, et al. Effectiveness of a community-based multifactorial intervention on falls and fall risk factors in community-living older adults: a randomized, controlled trial. J Gerontol 2007;62:1420-7.

63 Wyman J, Gross C, DiFabio R, et al. A randomized trial of exercise, education, and risk reduction counseling to prevent falls in population-based sample of older women. The Gerontologist 2005.
64 Salminen M, Vahlberg T, Kivelä S-L. The long-term effect of a multifactorial fall prevention programme on the incidence of falls requiring medical treatment. Public Health 2009;123:809-13.

65 Lau J, Schmid CH, Chalmers TC. Cumulative meta-analysis of clinical trials builds evidence for exemplary medical care. J Clin Epidemiol 1995;48:45-57. discussion $59-60$.

66 Sherrington C, Michaleff ZA, Fairhall N, et al. Exercise to prevent falls in older adults: an updated systematic review and meta-analysis. Br J Sports Med 2017;51:1750-8.

67 Cameron ID, Dyer SM, Panagoda CE, et al. Interventions for preventing falls in older people in care facilities and hospitals. Cochrane Database Syst Rev 2018;27. 